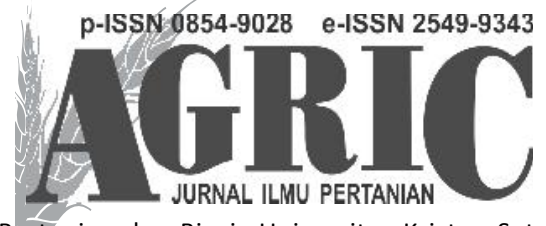

Fakultas Pertanian dan Bisnis Universitas Kristen Satya Wacana Jl. Diponegoro 52-60 SALATIGA 50711 - Telp. 0298-321212 ext 354

email: agric_fpb@yahoo.co.id, website: ejournal.uksw.edu/agric

\title{
PENGARUH CAMPURAN MEDIA TANAM TERHADAPPERTUMBUHAN TANAMAN STROBERI (Fragaria vesca L.) SEBAGAI TANAMAN HIAS TAMAN VERTIKAL
}

\section{EFFECTS OF GROWNG MEDIUM MIXTURES OF STRAWBERRY'S (Fragaria vesca L.) GROWTH AS ORNAMENTAL PLANTS IN VERTICAL GARDEN}

\author{
Naomi Endah Pratiwi, Bistok Hasiholan Simanjuntak, dan Dina Banjarnahor \\ Program Studi Agroteknologi \\ Fakultas Pertanian dan Bisnis, Universitas Kristen Satya Wacana \\ e-mail: naomiendah07@gmail.com
}

Diterima 12 April 2017, disetujui 31 Maret 2017

\begin{abstract}
Research on the effects of growing medium mixtures of strawberry's (Fragaria vesca L.) growth as ornamental plants in vertical garden was implemented from April to July 2016 in anexperimental field in Salaran Getasan Village. The purpose of this study were to 1) investigate the effects of different organic medium mixtures containing soil and rice husk, cocopeat, on compost banana stem on strawberry's growth and 2) determine the best mixture for strawberry's vertical system. The study was conducted using a randomized block design (RBD) with 10 treatments and four replications. The treatments included different compositions of soil and each material with a mixture ratio of 1: 1, 1:2 and 2: 1. Data were analyzed using analysis of variance and DMRT at $5 \%$ of error level as well as correlation test. Mixing organic medium as rice husk, cocopeat and compost banana stem with soil provided a significant influence on the number of leaves, number of Mixing organic medium as rice husk, cocopeat and compost banana stem with soil provided a significant influence on the number of leaves, number of shoot and shoot's dry weight. The best growing medium mixture for strawberry's growth was soil and rice husk with a ratio 2:1.
\end{abstract}

Keywords: strawberry, rice husk, cocopeat, compost banana stem and vertical garden 


\begin{abstract}
ABSTRAK
Penelitian tentang pengaruh pengujian media terhadap pertumbuhan dan hasil tanaman stroberi (Fragaria vesca L.) pada taman vertikal dilaksanakan sejak bulan April- Juli 2016 di lahan percobaan Salaran, Fakultas Pertanian dan Bisnis UKSW, Desa Getasan, Kecamatan, Laboratorium Tanah dan Laboratorium Benih UKSW. Tujuan dari penelitian ini yaitu untuk mengetahui pengaruh komposisi tanah dan media tanam organik arang sekam, cocopeat, dan kompos batang pisang dengan proporsi yang berbeda-beda terhadap pertumbuhan dan hasil tanaman stroberi (Fragaria vesca L.) pada sistem vertikal dan menentukan jenis dan komposisi media tanam organik yang memberikan pertumbuhan dan hasil terbaik pada sistem vertikal. Penelitian dilakukan menggunakan rancangan acak kelompok (RAK) dengan 10 perlakuan dan 4 kali ulangan, sehingga keseluruhan terdapat 40 satuan percobaan. Perlakuan yang dicobakan adalah komposisi bahan organik dengan campuran tanah masing- masing 1:1, 1:2, dan 2:1. Analisis data hasil pengamatan menggunakan metode sidik ragam dan uji DMRT pada taraf 5\% dan dilakukan uji korelasi. Hasil penelitian menunjukkan bahwa campuran media tanam organik berupa arang sekam, cocopeat dan pelepah/ batang pisang dan tanah memberikan pengaruh yang sangat nyata terhadap jumlah daun per tanaman, jumlah anakan per tanaman, berat brangkasan basah akar, berat brangkasan basah bagian atas tanaman, berat brangkasan kering akar dan berat brangkasan kering bagian atas tanaman. Campuran media tanam organik yang terbaik bagi pertumbuhan dan hasil tanaman stroberi dan untuk taman vertikal adalah media tanam organik berupa arang sekam dengan campuran tanah komposisi 2:1.
\end{abstract}

Kata kunci: stroberi, arang sekam, cocopeat, kompos batang pisang dan taman vertikal

\section{PENDAHULUAN}

Faktor penyebab utama penduduk kota di Indonesia sulit dalam hal bercocok tanam dan membuat taman adalah ketersediaan lahan yang semakin sedikit. Oleh sebab itu banyak taman vertikal atau yang dalam bahasa inggris artinya "Vertical Garden" dijumpai di pinggiran kotakota besar dan di sekitar pekarangan rumah. Taman vertikal yaitu taman yang dibuat dari kerangka besi, bambu, kayu dan kawat besi atau tembok yang menempel pada dinding. Menurut Ratih (2014) taman vertikal pertama kali diperkenalkan oleh Patrick Blanch seorang ahli botani dari Prancis pada tahun 1994, dilatar belakangi oleh semakin sempitnya lahan karena semakin maraknya pembangunan.

Taman vertikal merupakan kebun yang didesain membentuk arah vertikal atau bertingkat sehingga dapat mengoptimalkan lahan yang ada. Taman vertikal dapat ditanami dengan sayuran dengan masa panen yang cepat sehingga dapat menghemat pengeluaran atau sebagai green bank (penghijauan). Selain itu, taman vertikal dapat disusun secara bertingkat sehingga menambah estetika kebun di pekarangan rumah (Sari dkk., 2014).

Fungsi penggunaan vertical planting (penanaman secara vertikal) pada selubung bangunan antara lain: memelihara kualitas udara di sekitar bangunan, menyerap $\mathrm{CO}, \mathrm{CO}_{2}$ dan gas polutan lain, serta melepas $\mathrm{O}_{2}$. Desain vertical planting yang sampai pada permukaan tanah dapat difungsikan untuk aliran air hujan, menjamin kelestarian siklus air hujan untuk kembali ke tanah di malam hari, menjaga kelembaban udara di sekitar bangunan dan sebagai filter bagi aliran angin yang akan masuk ke dalam bangunan (Pranoto, 2008).

Komponen media tanam yang baik bagi pertumbuhan tanaman terdiri dari tanah, bahan organik, air dan udara. Komponen utama tanah untuk kehidupan tumbuhan yang optimal menurut Buckman dan Brady (1982) terdiri dari $50 \%$ ruang pori, $45 \%$ bahan mineral 
(anorganik) dan 5\% bahan organik. Akan tetapi, media tanam berupa tanah tergolong berat apabila di aplikasikan pada taman vertikal, sehingga mengakibatkan taman vertikal tidak bertahan lama. Sementara itu, menurut Decky (2015 dalam Taufani 2015), taman vertikal memerlukan media tanam yang ringan dan memiliki daya serap air serta hara yang tinggi. Media tanam yang sering digunakan pada taman vertikal adalah arang sekam, pasir, cocopeat, dan gambut. Akan tetapi, kajian komposisi media yang optimal untuk produksi tanaman di taman vertikal masih terbatas.

Menurut Komarayati dkk. (2003) dalam Supriyanto \& Fidryaningsih (2010) penambahan arang sekam pada media tumbuh akan menguntungkan karena dapat memperbaiki sifat tanah di antaranya adalah mengefektifkan pemupukan karena selain memperbaiki sifat fisik tanah (porositas, aerasi), arang sekam juga berfungsi sebagai pengikat hara (ketika kelebihan hara) yang dapat digunakan tanaman ketika kekurangan hara, hara dilepas secara perlahan sesuai kebutuhan tanaman/slow release.

Hasil penelitian Supriyanto \& Fidryaningsih Fiona (2010) penambahan arang sekam pada media tumbuh memberikan pengaruh nyata terhadap pertumbuhan tinggi semai jabon. Penambahan arang sekam dapat meningkatkan pertumbuhan tinggi semai jabon sebesar $18,31 \%-28,36 \%$.

Menurut Maspary (2011) arang sekam bersifat porous, ringan, tidak kotor, akan tetapi memiliki kemampuan menyerap air yang rendah dan porositas yang baik. Sifat ini menguntungkan jika digunakan sebagai media tanam karena mendukung perbaikan struktur tanah (Septiani, 2012).

Cocopeat merupakan proses penghancuran sabut dihasilkan serat atau fiber, serta serbuk halus (Irawan, dkk 2014). Salah satu media tanam tanpa tanah yang tersedia didaerah tropis adalah sabut kelapa atau dapat disebut sebagai cocopeat. Cocopeat adalah hasil pertanian yang didapatkan dari ekstraksi serat dari sabut kelapa. Cocopeat dianggap sebagai komponen media tanah yang baik dengan $\mathrm{pH}, \mathrm{EC}$ dan reaksi kimia lainnya. Cocopeat telah dikenal memiliki kapasitas menjerap air yang tinggi sehingga menyebabkan pergerakan udara dalam air buruk, aerasi yang rendah dapat mempengaruhi difusi oksigen ke akar (Awang dkk, 2009).

Cocopeat memiliki beberapa keunggulan sebagai media tanam. Salah satunya yang paling sering dimanfaatkan adalah kemampuan mengingat air (water holding capacity). Cocopeat memiliki kemampuan menyimpan air yang sangat besar, yaitu sebesar $69 \%$. (Anonim $^{\mathrm{b}}$, 2015). Kekurangan cocopeat adalah banyak mengandung tanin. Zat tanin diketahui sebagai zat yang menghambat pertumbuhan tanaman (Fahmi, 2015).

Menurut Irawan dkk (2014) cocopeat memiliki kemampuan menyerap air dan menggemburkan tanah. Menurut Rahman (2006) batang pisang memiliki bobot jenis $0,29 \mathrm{~g} / \mathrm{cm}^{3}$. Dengan demikian dapat dikatakan bahwa bobot jenis yang semakin kecil memiliki berat yang semakin ringan. Menurut hasil penelitian Wulandari dkk. (2011) kompos batang pisang mendukung pertumbuhan semai jabon. Penambahan komos batang pisang dan ofer (pupuk organik yang berasal dari kotoran hewan), memberikan pengaruh yang sama baik terhadap pertumbuhan semai jabon. Namun penambahan kompos batang pisang lebih baik bila dibandingkan dengan Tanah, andam (kompos yang berasal dari serasah daun), guano (pupuk organik yang berasal dari kotoran kelelawar) dan cocopeat.

Menurut hasil penelitian Pribadi dkk. (2015) pemberian kompos batang pisang dapat 
meningkatkan pertumbuhan semai jabon (Anthocephalus cadamba Miq.). Pemberian kompos batang pisang yaitu 7 minggu setelah tanam dengan dosis yang paling tinggi yaitu 375 gr/polybag merupakan perlakuan yang terbaik terhadap pertumbuhan tinggi semai jabon (Anthocephalus cadamba Miq.) yang mencapai 4,80 cm, pertambahan diameter sebesar 3,21 mm, berat kering sebesar 23,25 gr dan nilai rasio tajuk akar sebesar 2,44 gr.

Menurut Kusumawati (2015) batang pisang memiliki kandungan hara makro dan mikro yang sangat tinggi serta memiliki kandungan air yang tinggi sehingga cocok dijadikan kompos dan menurut Rahman (2006) batang pisang memiliki bobot jenis $0,29 \mathrm{~g} / \mathrm{cm} 3$. Dengan demikian dapat dikatakan bahwa bobot jenis yang semakin kecil memiliki berat yang semakin ringan. Oleh sebab itu, dalam penelitian ini dilakukan rekayasa berbagai macam media tanam organik untuk menciptakan pilihan- pilihan media yang memenuhi syarat.

Jenis tanaman yang digunakan untuk taman vertikal adalah tanaman stroberi (Fragaria $\times$ ananassa) merupakan salah satu tanaman yang dapat dibudidayakan secara vertikal. Dalam penelitian ini, uji coba kemampuan berbagai komposisi media tanam untuk mendukung pertumbuhan dan produksi tanaman pada sistem vertikal akan dilakukan pada tanaman stroberi.

Syarat pertumbuhan tanaman strawberi antara lain adalah: 1) curah hujan sebesar 600-700 $\mathrm{mm} /$ tahun, 2) lama penyinaran matahari sebanyak 8-10 jam tiap harinya, 3) dapat beradaptasi dengan baik di dataran tinggi tropis yang memilki temperatur $17-20^{\circ} \mathrm{C}$ dan 4 ) kelembapan udara yang baik untuk tanaman stroberi yaitu antara $80-90 \%$. Jika ditanam dalam pot media harus memiliki sifat porous, mudah merembeskan air dan unsur hara selalu tersedia. Ketinggian tempat yang memenuhi syarat iklim tersebut adalah 1000-1500 meter dpl (Tobing, 2010; Tohir, 1978 ).

Tanaman stroberi di Indonesia dalam setahun dapat berproduksi hingga lima kali, puncak produksi terjadi pada bulan Juli-Agustus tergantung keadaan lingkungan (Sukumalanandana dan Verheij, 1997) dalam Hanif (2012). Tanaman stroberi memiliki karakter yang tidak terlalu berat, pertumbuhan daun yang rimbun dan memiliki kecepatan tumbuh rendah hingga menengah (Anonim $\left.{ }^{\mathrm{a}}, 2015\right)$.

\section{METODE PENELITIAN}

Penelitian dilaksanakan selama 4 bulan, bulan April 2016 sampai dengan Juli 2016. Penelitian dilakukan di lahan percobaan Salaran, Fakultas Pertanian dan Bisnis, UKSW, Salatiga.

Alat yang digunakan dalam penelitian, antara lain: pelepah (batang) pisang, arang sekam, cocopeat, tanah, karung goni, pipa air, air, pompa, bambu, bibit stolon tanaman stroberi (Fragaria $\times$ ananassa). Rancangan dasar yang digunakan dalam penelitian ini adalah RAK (Rancangan Acak Kelompok) dengan 10 perlakuan dan diulang sebanyak 4 kali, menggunakan metode sidik ragam dengan uji F taraf 5\% dan dilakukan uji korelasi untuk mengetahui hubungan antar perlakuan. Pengaruh antar perlakuan digunakan uji D uncan's Multi Range Test (DMRT) taraf 5\% menggunakan software SAS ( Statistical Analysis System) dan menggunakan data rata-rata tertinggi dari semua parameter pertumbuhan dan hasil.

\section{HASIL DAN PEMBAHASAN}

\section{Media Tanam Awal}

Analisis media dilakukan diawal penelitian, hal ini bertujuan untuk mengetahui kandungan hara pada masing-masing perlakuan dari media 
tanam dengan campuran tanah sebelum proses penanaman tanaman Stroberi dimulai. Tabel 1 berikut adalah hasil analisis media tanam organik awal. dalam tanah. Kandungan fosfor dan kalium pada campuran media tanam tergolong rendah dan kandungan bahan organik dalam campuran media tanam tergolong sedang sampai rendah.

Tabel 1 Hasil Analisis Kimia Tanah Awal

\begin{tabular}{|c|c|c|c|c|c|}
\hline $\begin{array}{l}\text { Campuran } \\
\text { media tanam }\end{array}$ & $\mathrm{pH} \mathrm{H}_{2} \mathrm{O}$ & N Total $(\% N) P$ & Total $\left(\% \mathrm{P}_{2} \mathrm{O}_{5}\right)$ & $\begin{array}{l}\text { K Total } \\
\left(\% \mathrm{~K}_{2} \mathrm{O}\right)\end{array}$ & $\begin{array}{c}\text { Bahan } \\
\text { Organik } \\
\text { (\%BO) }\end{array}$ \\
\hline Tanah & $7,13^{N}$ & $0,01^{\mathrm{SR}}$ & $0,0298^{S R}$ & $0,06^{3 R}$ & $7,77^{\mathrm{ST}}$ \\
\hline AS $1: 1$ & $6,63^{N}$ & $0,30^{s}$ & $0,0413^{S R}$ & $0,18 \mathrm{SR}$ & $8,18^{5 T}$ \\
\hline AS $1: 2$ & $6,48^{\mathrm{N}}$ & $0,31^{\mathrm{s}}$ & $0,0441 \mathrm{SR}$ & $0,16 \mathrm{SR}$ & $9,02^{\mathrm{ST}}$ \\
\hline AS $2: 1$ & $7,06^{\mathrm{N}}$ & $0,52^{\mathrm{T}}$ & $0,0911^{S R}$ & $0,44 S R$ & $11,71^{\mathrm{st}}$ \\
\hline C $1: 1$ & $7,38^{N}$ & $0,05^{S R}$ & $0,0712^{S R}$ & $0,17 \mathrm{SR}$ & $11,87^{5 T}$ \\
\hline C $1: 2$ & $7,19 \mathrm{~N}$ & $0,01^{\mathrm{SR}}$ & $0,0274 \mathrm{SR}$ & $0,08 \mathrm{SR}$ & $10,98 \mathrm{sT}$ \\
\hline C $2: 1$ & $7,15^{\mathrm{N}}$ & $0,34^{s}$ & $0,0787 \mathrm{SR}$ & $0,21 \mathrm{SR}$ & $12,54 \mathrm{ST}$ \\
\hline K $1: 1$ & $7,26^{\mathrm{N}}$ & $0,03^{S R}$ & $0,0464 \mathrm{SR}$ & $0,30 \mathrm{SR}$ & $8,30^{\text {st }}$ \\
\hline K $1: 2$ & $7,28^{\mathrm{N}}$ & $0,01^{S R}$ & $0,0425 \mathrm{SR}$ & $0,25 \mathrm{SR}$ & $8,67 \mathrm{ST}$ \\
\hline K $2: 1$ & $7,98^{A K}$ & $0,01^{\mathrm{SR}}$ & $0,0354 \mathrm{SR}$ & $0,58 \mathrm{SR}$ & $8,17 \mathrm{st}$ \\
\hline
\end{tabular}

Pada Tabel 1 menunjukkan pH pada media Tanah atau tanah menunjukkan karakter tanah yang netral, begitupula pada media organik yang telah dicampur dengan tanah memiliki $\mathrm{pH}$ yang tergolong netral yaitu berkisar antara 6,487,98 pada masing-masing perlakuan. Menurut hasil penelitian Kurniawati dan Ariyani (2013) $\mathrm{pH}$ pada media organik berupa kompos alami (kompos dari bahan organik tanpa aktivator) maupun kompos Katalek (kompos dari bahan organik dengan aktivator Katalek) tergolong netral yaitu masing- masing sebesar 7,1 dan 6,4.

Kandungan nitrogen pada perlakuan media tanam tergolong tinggi, sedang sampai yang sangat rendah. Pada campuran media tanam berupa arang sekam komposisi 2:1 memiliki kandungan nitrogen yang tinggi dan campuran media tanam berupa arang sekam komposisi 1:1, 1:2, dan media cocopeat komposisi 2:1 tergolong memiliki kandungan nitrogen yang sedang. Menurut hasil analisis penelitian Sofyan dkk (2014) kandungan nitrogen pada media tanam organik berupa arang sekam sangat tinggi dibandingkan dengan kandungan nitrogen
Hasil analisis pada Tabel 1 menunjukkan bahwa kandungan hara Nitrogen, Fosfor dan Kalium pada campuran media tanam berupa arang sekam dan cocopeat dengan komposisi 1:1, 1:2, dan 2:1 hasilnya semakin tinggi. Akan tetapi, hal tersebut berbanding terbalik dengan media tanam organik berupa kompos dengan komposisi 1:1 sampai dengan 2:1.

Kandungan bahan organik yang paling tinggi adalah cocopeat dengan komposisi campuran yang paling tinggi yaitu $12,54 \%$ dibandingkan dengan perlakuan yang lainnya. Menurut hasil Kapasitas maksimal jerapan air adalah kemampuan media tanam dalam mengikat air secara maksimal karena adanya gaya gravitasi. Kapasitas maksimal jerapan air paling tinggi dari hasil analisis adalah campuran media tanam berupa cocopeat dengan komposisi 1:1 dan 2:1 yaitu masing-masing sebesar $110,15 \%$ dan $174,65 \%$.

Cocopeat memiliki beberapa keunggulan sebagai media tanam. Salah satunya yang paling sering dimanfaatkan adalah kemampuan mengikat air (water holding capacity). Menurut hasil analisis dari penelitian Irawan, A dan Y. 
Tabel 2 Hasil Analisis Fisika Media Tanam Awal

\begin{tabular}{cccccc}
\hline \multirow{2}{*}{$\begin{array}{c}\text { Campuran } \\
\text { media tanam }\end{array}$} & $\begin{array}{c}\text { Kapasitas Maksimal } \\
\text { Jerapan Air (\%) }\end{array}$ & \multicolumn{3}{c}{ Ruang Pori (\%) } & \multirow{2}{*}{ BI (g/ml) } \\
\cline { 3 - 5 } & & Air & Udara & Total & \\
\hline Tanah & 63,08 & 47,84 & 23,54 & 71,38 & 0,76 \\
AS $1: 1$ & 85,49 & 43,17 & 37,78 & 80,95 & 0,50 \\
AS $1: 2$ & 72,21 & 40,60 & 38,18 & 78,78 & 0,56 \\
AS $2: 1$ & 93,93 & 43,28 & 39,33 & 82,61 & 0,46 \\
C $1: 1$ & 110,15 & 45,61 & 38,76 & 84,37 & 0,41 \\
C $1: 2$ & 99,92 & 44,60 & 38,56 & 83,16 & 0,45 \\
C $2: 1$ & 174,65 & 50,97 & 38,02 & 88,99 & 0,29 \\
K $1: 1$ & 79,90 & 31,74 & 53,27 & 85,01 & 0,40 \\
K $1: 2$ & 94,67 & 62,95 & 11,95 & 74,91 & 0,66 \\
K $2: 1$ & 66,57 & 13,83 & 78,33 & 92,16 & 0,21 \\
\hline Ket : & AS : Arang Sekam, C: Cocopeat, dan K : Kompos & & & & \\
Analisis media tanam organik dilakukan sebelum tanam. & & & & & \\
- BI : bobot isi & & & & &
\end{tabular}

Kafiar (2015) kadar air yang dimiliki media cocopeat lebih tinggi dibandingkan dengan media arang sekam dan Tanah.

Tabel 2 menunjukkan bahwa bobot isi media tanam yang semakin besar memiliki ruang pori air media tanam yang semakin besar. Begitupula sebaliknya, bobot isi media tanam yang semakin kecil memiliki ruang pori air media tanam yang semakin kecil. Hal ini dikarenakan adanya hubungan antara bobot isi dengan ruang pori air dengan koefisien korelasi sebesar 0,626.

\section{Media Tanam Akhir}

Tabel 3 Hasil Analisis Kimia Campuran media tanam Akhir

\begin{tabular}{|c|c|c|c|c|}
\hline $\begin{array}{l}\text { Campuran } \\
\text { media tanam }\end{array}$ & N Total (\%N) & P Total $\left(\% \mathrm{P}_{2} \mathrm{O}_{5}\right)$ & $\mathbf{K}$ Total $\left(\% \mathbf{K}_{2} \mathbf{O}\right)$ & $\begin{array}{c}\text { Bahan } \\
\text { Organik } \\
\text { (\%BO) }\end{array}$ \\
\hline Tanah & $0,01^{\mathrm{SR}}$ & $0,03 \mathrm{SR}$ & $0,03 \mathrm{SR}$ & 6,99 ST \\
\hline AS $1: 1$ & $0,01^{\mathrm{SR}}$ & $0,06^{\mathrm{SR}}$ & $0,06 \Omega \mathbb{R}$ & $10,00^{5 T}$ \\
\hline AS 1:2 & $0,01^{\mathrm{SR}}$ & $0,05 \mathrm{SR}$ & $0,04 \mathrm{SR}$ & $8,65^{3 T}$ \\
\hline AS $2: 1$ & $0,12^{\mathrm{SR}}$ & $0,07 \mathrm{SR}$ & $0,06 \mathrm{SR}$ & 9,01 sT \\
\hline C $1: 1$ & $0,02^{S R}$ & $0,06^{\mathrm{SR}}$ & $0,04 S R$ & $9,54 \mathrm{ST}$ \\
\hline C $1: 2$ & $0,01^{\mathrm{SR}}$ & $0,03 \mathrm{SR}$ & $0,03 \Omega R$ & $8,70^{\mathrm{ST}}$ \\
\hline C $2: 1$ & $0,02^{S R}$ & $0,09 \mathrm{SR}$ & $0,10^{S R}$ & $9,53 \mathrm{sT}$ \\
\hline $\mathrm{K} 1: 1$ & $0,01^{\mathrm{SR}}$ & $0,05 \mathrm{SR}$ & $0,04 \mathrm{SR}$ & $9,08^{\mathrm{ST}}$ \\
\hline K $1: 2$ & $0,01^{\mathrm{SR}}$ & $0,04 \mathrm{SR}$ & $0,04^{S R}$ & $7,94 \mathrm{ST}$ \\
\hline $\mathrm{K} 2: 1$ & $0,01^{\mathrm{SR}}$ & $0,04^{S R}$ & $0,08 \mathrm{SR}$ & $8,59 \mathrm{sT}$ \\
\hline $\begin{array}{l}\text { Ket : } \\
\text { AS : Arang Seka } \\
\text { Kriteria hasil an } \\
\text { dan sangat tingg } \\
\text { Sangat Tmggi. } \\
\text { Analisis media t }\end{array}$ & $\begin{array}{l}\text { : Cocopeat, dan F } \\
\text { tanah msam, aga } \\
\text { lasifikasi menurut } \\
\text { organik dilakukar }\end{array}$ & $\begin{array}{l}\text { mpos } \\
\text { sam, netral, agak alke } \\
P, 2012) . S R=\text { Sanga } \\
\text { lah panen. }\end{array}$ & $\begin{array}{l}\text { kalis, rendah, sangat } \\
\text { dah, } \mathrm{R}=\mathrm{Rendah}, \mathrm{S}=\mathrm{Se}\end{array}$ & $\begin{array}{l}\text { sedang, } t \\
I=\text { Tinggi, }\end{array}$ \\
\hline
\end{tabular}

Data analisis media tanam akhir menunjukkan bahwa kandungan hara Nitrogen, Fosfor dan Kalium dari campuran media tanam tergolong sangat rendah. Kandungan bahan organik dari campuran media tanam tergolong sangat tinggi. Hal tersebut diduga dapat disebabkan karena proses dekomposisi oleh mikroorganisme dalam tanah masih berlangsung.

\section{Pengaruh Berbagai Macam Campuran MediaTanam OrganikTerhadapPertumbuhan Tanaman Stroberi}

Dalam menentukan atau memilih campuran media tanam yang terbaik, tidak hanya dilihat dari kandungan unsur hara yang dimiliki, akan tetapi pertumbuhan tanaman dapat menjadi indikator dalam memilih media tanam yang terbaik. Oleh sebab itu dilakukan pengujian pengaruh antar keduanya, komponen pertum- 
buhan tanaman stroberi yang digunakan meliputi jumlah daun per tanaman, jumlah tunas per tanaman dan luas daun. Berikut adalah data hasil analisis pertumbuhan tanaman: arang sekam 1:2, cocopeat $1: 1,1: 2$ dan kompos batang pisang komposisi 1:1 akan tetapi tidak memiliki perbedaan yang nyata terhadap tanaman yang ditanam pada media

Tabel 4 Data Pertumbuhan Tanaman Stroberi

\begin{tabular}{|c|c|c|c|}
\hline $\begin{array}{c}\text { Campuran media } \\
\text { tanam }\end{array}$ & $\begin{array}{c}\text { Inmlah I)ann } \\
\text { Tanaman }\end{array}$ & $\begin{array}{c}\text { Inmlah Tunasi } \\
\text { Tanaman }\end{array}$ & Luas Daun $\left(\mathrm{cm}^{2}\right)^{*}$ \\
\hline Tanah & $13,6 \mathrm{l}$ abc & 1,74 a & $5,61 \quad 2$ \\
\hline AS $1: 1$ & $11,00 \mathrm{a}$ & $2.19 \mathrm{~b}$ & $7.80 \mathrm{a}$ \\
\hline AS $1: 2$ & $16,79 \mathrm{c}$. & 1.74 a & $8,28=$ \\
\hline$\Lambda S 2: 1$ & $16,53 \mathrm{c}$ & $2,03 \mathrm{ab}$ & 9,30 a \\
\hline C $1: 1$ & 13,14 abc & $1,74 \mathrm{~d}$ & 7,01 a \\
\hline C $1: 2$ & $11,81 \mathrm{ab}$ & 1,76 a & $6,79 \quad \mathrm{a}$ \\
\hline C $2: 1$ & $14,33 \mathrm{abc}$ & $1.92 \mathrm{ab}$ & $7.80 \mathrm{a}$ \\
\hline $\mathrm{K} 1: 1$ & 14,11 abe & 1,67 ג & 12,17 त \\
\hline $\mathrm{K} 1: 2$ & $16,10 \mathrm{bc}$ & $1,92 \mathrm{ab}$ & 9,78 a \\
\hline K $2: 1$ & $15,31 \mathrm{abc}$ & $2,07 \mathrm{ab}$ & $11,58 \mathrm{a}$ \\
\hline
\end{tabular}

Campuran media tanam memberikan pengaruh yang nyata terhadap jumlah daun dan jumlah tunas. Tanaman yang ditanam pada media tanam arang sekam dengan komposisi 1:2 dan 2:1 memiliki jumlah daun yang nyata lebih tinggi dibanding dengan tanaman yang tumbuh pada media tanam arang sekam dengan komposisi 1:1 dan cocopeat dengan komposisi 1:2 akan tetapi tidak memiliki perbedaan yang nyata terhadap tanaman yang ditanam pada media tanam tanah dan cocopeat dengan komposisi 1:1, 2:1 dan kompos batang pisang. Tanaman yang ditanam pada media tanam arang sekam dengan komposisi 1:1 memiliki jumlah tunas yang nyata lebih tinggi dibanding dengan tanaman yang tumbuh pada media tanam tanah, arang sekam 2:1, cocopeat 2:1, kompos batang pisang komposisi 1:2 dan 2:1 (Tabel 4).

Tingginya jumlah daun dan jumalah tunas pada tanaman yang ditanam pada media tanam arang sekam dapat disebabkan karena tingginya kandungan unsur hara Nitrogen, Fosfor dan Kalium pada arang sekam serta mendukung perbaikan struktur tanah. Mernurut Septiani (2012) arang sekam dapat digunakan sebagai media tanam karena mendukung perbaikan struktur tanah karena aerasi dan drainase menjadi lebih baik.

Akan tetapi campuran media tanam tidak memberikan pengaruh yang nyata terhadap luas daun. Hal ini dapat disebabkan karena rata-

Tabel 5 Data Biomassa Tanaman Stroberi

\begin{tabular}{|c|c|c|c|c|c|}
\hline \multirow{2}{*}{$\begin{array}{c}\begin{array}{c}\text { Campuran } \\
\text { media tanam }\end{array} \\
\text { Tanah }\end{array}$} & \multirow[t]{2}{*}{$\begin{array}{c}\begin{array}{c}\text { Berat } \\
\text { Berangkasan } \\
\text { Basah Akar } \\
\text { Tanaman (g)* }\end{array} \\
18,16 \text { a }\end{array}$} & \multirow[t]{2}{*}{$\begin{array}{c}\text { Berat } \\
\begin{array}{c}\text { Berangkasan } \\
\text { Basah Bagian } \\
\text { Atas Tanaman } \\
(\mathrm{g})^{*}\end{array} \\
9,52 \mathrm{a}\end{array}$} & $\begin{array}{c}\text { Berat } \\
\text { Berangkasan } \\
\text { Kering Akar } \\
\text { Tanaman (g)* }\end{array}$ & \multicolumn{2}{|c|}{$\begin{array}{c}\text { Berat } \\
\text { Berangkasan } \\
\text { Kering Bagian } \\
\text { Atas Tanaman } \\
(\mathrm{g})^{* *}\end{array}$} \\
\hline & & & 4,91 a & 3,00 & $\mathrm{a}$ \\
\hline AS $1: 1$ & 24,46 a & $7,88 \mathrm{a}$ & 7,80 a & 2,65 & a \\
\hline AS $1: 2$ & 41,41 a & 21,90 a & 10,84 a & 4,31 & $a b$ \\
\hline AS $2: 1$ & 38,53 a & 20,38 a & 11,26 a & 3,12 & a \\
\hline C $1: 1$ & 26,56 a & $10,30 \mathrm{a}$ & 5,78 a & 2,60 & a \\
\hline C $1: 2$ & 30,67 a & 10,83 a & 5,92 a & 2,31 & a \\
\hline C 2:1 & 41,28 a & 12,78 a & 7,98 a & 2,86 & a \\
\hline K 1:1 & 22,20 a & 14,63 a & 5,26 a & 3,87 & $a b$ \\
\hline K $1: 2$ & 29,24 a & 14,50 a & 10,47 a & 4,09 & $a b$ \\
\hline K $2: 1$ & 44,22 a & 23,99 a & 10,87 a & 5,48 & b \\
\hline $\begin{array}{l}\text { Angka-ang } \\
\text { antar perlak } \\
\text { - } \\
\left({ }^{*}\right) \text { Koding } \\
\left(*^{* *} \text { Koding }\right.\end{array}$ & rlakuan h. & nasi data me & $\begin{array}{l}\text { est) pada tara } \\
\log (\mathbf{x}+2) \text {. } \\
\text { in } \sqrt{x} \text {. }\end{array}$ & & \\
\hline
\end{tabular}


rata kandungan hara nitrogen tergolong sangat rendah. Menurut Morton dan Watson (948) dalam Febrian dkk. (2013) pada tanaman yang kekurangan Nitrogen daunnya lebih kecil apabila dibandingkan dengan tanaman yang mendapat cukup Nitrogen.

Variabel atau parameter yang diuji untuk mengetahui pengaruh berbagai macam campuran bahan organik terhadap pertumbuhan tanaman stroberi adalah biomassa tanaman atau berat brangkasan tanaman. Campuran media tanam tidak memberikan pengaruh yang nyata terhadap berat brangkasan basah akar, berat brangkasan basah bagian atas tanaman dan berat brangkasan kering akar. Tanaman yang ditanam pada media tanam kompos batang pisang dengan komposisi 2:1 memiliki berat brangkasan kering bagian atas tanaman yang nyata paling tinggi dibanding dengan tanaman yang ditanam pada media tanam tanah, arang sekam cocopeat dan kompos batang pisang dengan komposisi 1:1 dan 1:2.

Berat brangkasan kering bagian atas tanaman memiliki perbedaan yang nyata terutama pada media tanam kompos batang pisang (Tabel 5). Hal ini dapat disebabkan adanya hubungan antara luas daun dengan berat brangkasan kering bagian atas tanaman dengan koefisien korelasi 0,761. Menurut hasil penelitian Pribadi dkk (2015) menyatakan bahwa penambahan kompos batang pisang dapat meningkatkan pertumbuhan tinggi $4,80 \mathrm{~cm}$, pertambahan diameter 3,21 mm, berat kering 23,25 gr dan nilai rasio tajuk akar 2,44 gr selama 7 minggu pada tanaman semai jabon (Anthocephalus cadamba Miq).

\section{Campuran media tanam yang Terbaik}

Pada penelitian ini, untuk menentukan campuran media tanam yang terbaik dapat dilakukan dengan cara kuantitatif. Data kuantitatif diperoleh dengan cara skoring dari rata- rata variabel unsur hara, pertumbuhan dan hasil tanaman stroberi yang kemudian di jumlah.

Hasil data kuantitatif dengan cara skoring dari rata- rata variabel unsur hara, pertumbuhan dan hasil tanaman stroberi diperoleh data jumlah. Jumlah yang terbesar dari data jumlah skoring menunjukkan bahwa campuran media tanam yang terbaik adalah arang sekam dengan komposisi 2:1 dengan jumlah 110 (Tabel 6).

\section{KESIMPULAN}

Dari hasil penelitian yang telah dilakukan dapat diambil kesimpulan bahwa:

1. Campuran media tanam berupa arang sekam, cocopeat dan pelepah/batang pisang dan tanah memberikan pengaruh yang sangat nyata terhadap jumlah daun per tanaman, jumlah tunas per tanaman dan berat kering bagian atas tanaman.

Tabel 6 Skoring Data Rata- Rata Tertinggi dari Semua Parameter Pertumbuhan dan Hasil

\begin{tabular}{|c|c|c|c|c|c|c|c|c|c|c|c|c|c|c|c|}
\hline \multirow{2}{*}{$\begin{array}{c}\text { Campuran } \\
\text { media tanam }\end{array}$} & \multicolumn{15}{|c|}{ Variabel Pengamatan } \\
\hline & $\mathbf{N}$ & $\mathbf{P}$ & $\mathbf{K}$ & BO & KJM & RPT & BI & JD & JT & LD & BBA & BBB & BKA & BKB & $\mathbf{J m l}$ \\
\hline Tanah & 2 & 2 & 1 & 1 & 5 & 2 & 9 & 4 & 3 & 1 & 1 & 2 & 1 & 5 & 39 \\
\hline AS $1: 1$ & 7 & 4 & 5 & 3 & 8 & 4 & 7 & 1 & 10 & 4 & 3 & 1 & 6 & 3 & 66 \\
\hline AS $1: 2$ & 8 & 6 & 3 & 6 & 4 & 3 & 8 & 10 & 2 & 6 & 9 & 9 & 8 & 9 & 91 \\
\hline AS $2: 1$ & 10 & 10 & 9 & 8 & 7 & 7 & 4 & 9 & 8 & 7 & 7 & 8 & 10 & 6 & 110 \\
\hline C $1: 1$ & 6 & 8 & 4 & 9 & 9 & 8 & 3 & 3 & 4 & 3 & 4 & 3 & 3 & 2 & 69 \\
\hline C $1: 2$ & 3 & 1 & 3 & 7 & 2 & 5 & 6 & 2 & 5 & 2 & 6 & 4 & 4 & 1 & 51 \\
\hline C $2: 1$ & 9 & 9 & 6 & 10 & 10 & 9 & 2 & 6 & 7 & 5 & 8 & 5 & 5 & 4 & 95 \\
\hline $\mathrm{K} 1: 1$ & 5 & 7 & 8 & 4 & 3 & 6 & 5 & 5 & 1 & 10 & 2 & 7 & 2 & 7 & 72 \\
\hline K $1: 2$ & 4 & 5 & 7 & 5 & 1 & 1 & 10 & 8 & 6 & 8 & 5 & 6 & 7 & 8 & 81 \\
\hline K $2: 1$ & 1 & 3 & 10 & 2 & 6 & 10 & 1 & 7 & 9 & 9 & 10 & 10 & 9 & 10 & 97 \\
\hline
\end{tabular}


2. Campuran media tanam yang terbaik bagi pertumbuhan dan hasil tanaman stroberi dan untuk taman vertikal adalah media tanam organik berupa arang sekam dengan campuran tanah komposisi 2:1 dan dengan bobot total media $265 \mathrm{~g}$.

\section{SARAN}

Perlu dilakukan penelitian lebih lanjut mengenai pengujian berbagai tanaman hias menggunakan media arang sekam 2:1 sehingga dapat menambah estetika pada taman vertikal.

\section{DAFTAR PUSTAKA}

Anonim ${ }^{\mathrm{a}}$. 2015. Membuat Taman Vertikal di Rumah - Tren- ASBINDO - Asosiasi Bunga Indonesia, Mitra Anda dalam Florikultura. http://www.asbindo.org/ tren/membuat-taman-vertikal-dirumah.pdf. Diakses 31 Oktober 2015, pukul 13.15 WIB.

Awang, Y., Anieza Shazmi Shaharom, Rosli B. Mohamad dan Ahmad. 2009. Chemical and Physical Characteristics of Cocopeat-Based Media Mixtures and Their Effects on the Growth and Development of Celosia Cristata. American Journal of Agricultural and Biological Sciences 4 (1): 63-71, 2009 ISSN 1557-4989.

Buckman, H dan Brady. 1982. Ilmu Tanah. PT Bhratara Karya Aksara. Jakarta.

Fahmi, Z. Ismail. 2015. Media Tanam sebagai Faktor Eksternal yang Mempengaruhi Pertumbuhan Tanaman. Balai Besar Perbenihan dan Proteksi Tanaman Perkebunan Surabaya. http:// ditjenbun.pertanian.go.id. Diunduh pada tanggal 4 Desember 2016, pukul 22.00 WIB.
Febrian, I. Faris, Mukhammad Muryono dan Febri Hendrayana. 2013. Pupuk Nitrogen terhadap Pertumbuhan dan Produktivitas Tembakau (Nicotiana tabacum L.) Varietas Prancak pada Kepadatan Populasi 36000/ha di Kabupaten Pamekasan, Jawa Timur. Jurusan Biologi, Fakultas Matematika dan Ilmu Pengetahuan Alam Institut Teknologi Sepuluh Nopember. Surabaya.

Hanif, Zainuri. 2012. Sebaran Stroberi (Fragaria $x$ ananassa) di Indonesia. https://zainuri.wordpress.com/2012/07/ 15/sebaran-stroberi-fragaria-ananassadi-indonesia/. Diakses pada tanggal 29 November 2016. Pukul 22.52 WIB.

Irawan, A dan Hanif Nurul Hidayah. 2014. Kesesuaian Penggunaan Cocopeat sebagai Media Sapih pada Politube dalam Pembibitan Cempaka (Magnolia elegans (Blume.) H.Keng). Jurnal WASIAN Vol.1 No.2 Tahun 2014:73-76.

Irawan, A dan Y. Kafiar. 2015. Pemanfaatan Cocopeat dan Arang Sekam Padi Sebagai Media Tanam Bibit Cempaka Wasian (Elmerrilia Ovalis). Jurnal PROS SEMNAS MASY BIODIV INDON Volume 1, Nomor 4, Juli 2015 ISSN: 2407- 8050. Halaman: 805- 808.

Kurniawati, F dan M. Ariyani. 2013. Pengaruh Media Tanam dan Pemupukan Npkterhadap Pertumbuhan Bibit Damar Mata Kucing (Shorea javanica). Jurnal Ilmu Tanah dan Agroklimatologi Volume 10, Nomor 1

Kusumawati, A. 2015. Analisa Karakteristik Pupuk Kompos Berbahan Batang Pisang. Seminar Nasional Universitas PGRI Yogyakarta 2015 ISBN 978-602- 
73690-3-0323 Universitas PGRI Yogyakarta.

Pranoto, M. 2008. Multilevel Urban Green Area: Solusi terhadap Global Warming dan High Energy Building. Jurnal Rekayasa Perencanaan, Vol.4,No.3.

Pribadi, C., M. Mardhiansyah, Evi Sribudiani. 2015. Aplikasi Kompos Batang Pisang terhadap Pertumbuhan Semai Jabon (Anthocephalus cadambaMiq.) pada Medium Gambut. Jom Faperta Vol. 2 No. 1 Februari 2015

Rahman, H. 2006. Pembuatan Pulp dari Batang Pisang Uter (Musa paradisiaca Linn. var uter) Pascapanen dengan Proses Soda. Skripsi, Fakultas Kehutanan. Universitas Gadjah Mada. Yogyakarta.

Ratih, Widiastuti. 2014. Evaluasi Termal Dinding Bangunan dengan Vertical Garden. Jurnal PPKM UNSIQ I (2014) 1-12. ISSN: 2354-869X.

Sari, M., Ai Nurjanah, Lidhia Fairuz Harly. 2014. Vertical Garden sebagai Green Bank dalam Usaha Optimalisasi Lahan pada Kawasan Lingkungan Padat Penduduk di Kota BandungJawa Barat. Universitas Pendidikan Indonesia Bandung. Bandung.

Septiani, D. 2012. Pengaruh Pemberian Arang Sekam Padi terhadap Pertumbuhan dan Hasil Tanaman Cabai Rawit (Capsicum frutescens). Politeknik Negeri Lampung. Lampung.

Sofyan, S.E., Melya Riniarti dan Duryat. 2104. Pemanfaatan Limbah Teh, Sekam Padi, dan Arang Sekam sebagai Media Tumbuh Bibit Trembesi (Samanea saman). Jurnal Sylva Lestari Vol. 2 No. 2, Mei 2014 (61-70). ISSN 23390913.

Supriyanto dan Fidryaningsih. 2010. Pemanfaatan Arang Sekam untuk Memperbaiki Pertumbuhan Semai Jabon (Anthocephalus cadamba (Roxb.) Miq) pada Media Subsoil. Jurnal SILVIKULTUR TROPIKA Vol. 01 No. 01 Desember 2010, Hal. 24 28. ISSN: 2086-8227.

Taufani, A. 2015. Kreativitas yang Tak Terhingga pada Upaya Asimilasi Tanaman dengan Bangunan Kini Tidak Hanya Dikembangkan Secara Horizontal, Tapi Juga Vertikal. Indesignlive. Asia

Tobing, M. U. 2010. Evaluasi Pengelolaan Tanaman Strawberi (Fragaria Vesca) di Desa Kalisoro, Blumbang dan Gondosuli Kecamatan Tawangmangu Kabupaten Karanganyar. Skripsi Jurusan/ Progdi Ilmu Tanah. Fakultas Pertanian Universitas Sebelas Maret Surakarta. Surakarta.

Wulandari, A., Irdika Mansur, dan Helga Sugiarti. 2011. Pengaruh Pemberian Kompos Batang Pisang terhadap Pertumbuhan Semai Jabon (Anthocephalus cadamba Miq.). Jurnal Silvikultur Tropika. Vol. 03 No. 01 Agustus 2011, Hal. 78 - 81. ISSN: 2086-8227. 